As an example of the successful accomplishment of a difficult task, we reproduce (Fig. I) the photograph of kittiwake gulls nesting on the precipitous face of a cliff, approach to which was effected by climbing down a narrow gulley and then scrambling over seaweed-clad boulders, to the imminent peril of the camera.

As a specimen of really excellent bird-photography, we present to our readers the picture of a group of young ringed plovers (Fig. 2), the mottled down of which harmonises so admirably at a short distance with their surroundings.

If it be said that this notice is purely commendatory, and contains nothing in the way of criticism, the reply is that we have found nothing to criticise or to condemn. It is real nature-study.

\section{THE ARTIFICIAL PRODUCTION OF RUBIES BY FUSION. ${ }^{1}$}

T HIS memoir opens with a short historical account of the attempts previously made to produce rubies by fusion, starting with the researches undertaken by Gaudin with the view of obtaining fused alumina in a transparent state. $\mathrm{He}$ obtained by fusing potassium or ammonium alum, together with a little chrome alum, small globules, which became opaque on solidification, but had the composition of the ruby. These were shown by Becquerel to have the cleavage of corundum, and contained small cavities lined with crystals of ruby. Gaudin concluded that alumina could not exist in the vitreous state, and this view was supported by C. Sainte-Claire Deville, on account of the uniform density of the oxide before and after fusion. The facts at present known are in support of this view, for the transparent alumina obtained by fusion is a completely crystalline mass. The problem was not further investigated until, in I886, Charles Friedel described an experiment by which corundum was obtained by fusion, presenting most of the properties of the ruby, but differing from the natural product by the presence of certain included bubbles, and by a rather low density.

As the production of the so-called "Geneva rubies" remained a trade secret, $M$. Verneuil started a series of investigations, following up the work of Gaudin. $\mathrm{He}$ found that to obtain the fused material in a transparent state certain conditions must be rigorously fulfilled. $\mathrm{He}$ compares the solidification of alumina to that of water, which forms according to the method of cooling transparent or opaque ice. An important observation which appears to have escaped Gaudin is that it is only the portions of alumina which are fused in the cooler parts of the flame which remain transparent on solidification. One of the greatest experimental difficulties is that, however carefully the cooling is conducted, the fused mass is excessively brittle. This brittleness is least marked when a very small supporting surface is employed. The apparatus devised by $M$. Verneuil is very ingenious. The blow-pipe and furnace tube must be absolutely vertical. The finely powdered alumina, containing the requisite quantity of chromic oxide, and specially purified, is admitted by means of a fine sieve, which is given a series of regular taps, controlled by an electromagnet, so that the material falls down the tube intermittently in a series of thin layers. It forms a cone at the bottom, and as soon as this cone reaches a hot enough part of the tube the apex fuses, and the fused material then extends gradually upwards in a long filament. This eventually reaches a still hotter part of the furnace, and develops a spherical mass instead of growing further;

1 "Memoire sur la Reproduction artificielle du Rubis par Fusion." By A. Verneuil. (Annales de Chimie et de Physique, 8 esérie, t. ii., September.) NO. I 834, VOL. 7 I ] this spherical globule when solidified forms the ruby. The cooling has to be very gradual, so that the crystalline particles have time to become regularly arranged, or an opaque product is obtained. If the ovoid mass is carefully detached when cold, it splits up into two nearly equal portions, but not along a cleavage-plane. The product so obtained is an individual crystal, and the direction of its principal optic axis is never very different from that of the major axis of the ovoid.

The product when cut cannot be distinguished by its chemical, physical, or optical properties from a stone cut from a natural ruby. The operation may be considered successful when the clear product weighs $\mathrm{I}_{2}$ to $\mathrm{I}_{5}$ carats, and has a real diameter of 5 or 6 millimetres. It is, however, impossible to obtain stones larger than $\frac{1}{4}$ carat free from included bubbles and cracks, and experts can therefore readily distinguish the artificial gems from natural ones. These flaws do not in any way detract from the beauty of the stones; they are often clearer than many natural rubies, which are seldom found perfect.

The paper is illustrated by diagrams of the very ingenious apparatus devised by the author.

\section{CALCIUM METAL}

GLECTROMETALLURGY has at last succeeded in producing metallic calcium in commercial quantities, and at what must be considered a relatively low price. Until within a few weeks ago this metal had only been available in very small amounts, and remained a rare laboratory specimen; it is now obtainable at a price per kilogram less than that charged by most chemical dealers for a small one-gram sample. Humphry Davy first formed the amalgam by electrolysing lime, mixed with mercuric oxide and slightly moistened, with a mercury kathode; he isolated the metal in small quantities by distilling off the mercury. Since then many chemists have tried in vain to find a method suitable for its preparation on a larger scale. Matthiesen, making use of Bunsen's suggestion of applying high current density at the kathode, only succeeded in obtaining a few grams at a time by electrolysis of the fused chloride, or of mixtures of calcium and other chlorides having a lower fusing point. Henri Moissan, as the result of a critical study of the numerous proposed methods, was able to prepare somewhat larger quantities of the metal. His method was essentially a modification of that proposed by LièsBodart and Jobin in 1858 , which consisted in reducing fused calcium iodide with metallic sodium. Moissan found that molten sodium forms an excellent solvent for calcium, and by heating calcium iodide with a large excess of sodium obtained on cooling a cake of the sodium-calcium alloy resting on the sodium iodide. Small quantities of the alloy were thrown into well cooled absolute alcohol, which reacts with the sodium leaving the calcium pure, but in the state of a fine crystalline powder. This powder can be agglomerated by pressure and fusion, and thus Moissan prepared the fine specimen ingots of this metal which so greatly interested visitors to the Paris Exhibition of I900. It is largely to him that we are indebted for a knowledge of the properties of the pure metal, of which he prepared some 4 kilos. by this process. Contrary to the earlier descriptions, calcium is a white metal, the yellow coloration being due to a film of nitride; its melting point is about $760^{\circ} \mathrm{C}$., and its density $\mathrm{r} .85$. The definite compounds which it forms directly with hydrogen and nitrogen promise useful applications in the laboratory in cases where it is necessary to remove these gases.

The next advance was made almost simultaneously by Borchers and Stockem at Aix-la-Chapelle, and 
Ruff and Plato at Berlin. The method employed by these workers was in principle that of Matthiesen, but by suitable construction of apparatus and regulation of temperature much better yields were obtained, and the metal was thus prepared in larger quantities. Borchers and Stockem electrolysed molten calcium chloride, which was maintained at a temperature below the fusing point of calcium; they ascribe the low yields at higher temperatures to the reaction of fused calcium with calcium chloride to form a subchloride. Using an iron rod as kathode, they obtained a metal sponge which was pressed with tongs before removing from the electrolyte. The raw material prepared in this way contained some ro per cent. of calcium chloride, which could, however, be almost entirely removed by subsequent fusion of the metal.

The final step in the evolution of the commercial process was taken by Suter and Redlich, of the Elektrochemische-Werke, Bitterfeld. By the ingenious employment of a kathode which only just touches the surface of the fused calcium chloride, they obtain a small layer of fused calcium under the kathode; before the calcium has collected in sufficient amount to flow away the electrode is very slightly raised; the metal thus comes into a cooler zone and solidifies. By continuing the process a rather irregular rod of calcium is built up, which itself forms the kathode. The metal is supplied in these rough rods, which in outward appearance strongly resemble cabbage stalks, but show a white metallic surface when cut through.

The present price quoted in Germany is about 20 s. a kilogram retail, or $12 s$, a kilo. in roo kilogram lots, which quotation alone proves the feasibility of the process. The technical product is said to contain about 97. I I per cent. pure calcium, I.64 per cent. calcium chloride, and 0.4 per cent. sodium. If one may judge by the case of metallic sodium, there will doubtless be difficulties in finding any large demand for the metal, but it will obviously be much appreciated for experimental purposes in many chemical and physical laboratories.

R. S. Hutton.

\section{NOTES}

We regret to announce that Sir Lowthian Bell, Bart., F.R.S., died on 'Tuesday, at eighty-eight years of age.

THE death of Mr. Norman Maccoll, late editor of the Athenaeum, at sixty-one years of age, will be deeply regretted by many men of science. Mr. Maccoll did much to further the interests of science, and to cultivate sympathy with the pursuit of natural knowledge among readers not actively engaged in scientific work.

ON Saturday last, direct telegraphic communication was established between Liverpool and Teheran, in Persia, a distance of four thousand miles. The line belongs to the Indo-European Telegraph Company.

ON Tuesday next, December 27, Mr. Henry Cunynghame will deliver at the Royal Institution the first of a Christmas course of six lectures adapted to a juvenile auditory on ancient and modern methods of measuring time, experimentally illustrated.

Aт the December meeting of the Astronomical Society of France an address was given by $\mathrm{Mr}$. de Watteville on the temperatures of stars. The lecturer described a series of experiments made by him in the Count de Labaume Pluvinel laboratory, and exhibited a series of photographs of spectra obtained by him, reproducing the principal types described by Sir Norman Lockyer. The president congratulated the speaker on having obtained such brilliant results, on the subject of which he has already delivered a thesis at the Sorbonne.

$$
\text { NO. I } 834 \text {, VOL. } 7 \text { I J }
$$

IT is announced by the Athenaeum that the Circolo Matematico di Palermo intends to offer an international prize for geometry at the fourth International Mathematical Congress, which will meet at Rome in 1908. The prize will consist of a small gold medal, to be called the Guiccia medal, after its founder, and of 3000 francs, and will be given by preference, though not necessarily, to an essay which advances the knowledge of the theory of algebraical curves of space. The treatises may be written in Italian, French, German, or English, and must be sent to the president of the Circolo Matematico before July I, 1907 .

WE learn from the Times that on Friday last President Loubet received Dr. Otto Nordenskjöld, who was presented by the Minister for Sweden and Norway in Paris. On the evening of the same day Dr. Nordenskjöld delivered a lecture on his Antarctic explorations before the French Geographical Society. Prince Gustav Adolph and Prince William of Sweden were present, and several Ministers were represented. Dr. Nordenskjöld was the guest on Saturday afternoon of the Paris Municipal Council at the Hottel de Ville. He was welcomed by the president of the council, who presented him with a silver medal commemorating his visit to the city. On Saturday evening Dr. Nordenskjöld delivered a lecture before a large and distinguished audience at the Sorbonne.

THE death is announced of $\mathrm{Mr}$. C. G. Barrett, one of the editors of the Entomologist's Monthly Magazine, at the age of sixty-eight years.

IT is stated that at a meeting of the French Surgical Society held on December $\mathrm{r}_{4}$ a report of the committee appointed to investigate Dr. Doyen's researches on cancer and its microbe was read, and that some of the conclusions support Dr. Doyen's claims. No authentic details have, however, as yet been published.

THE following recent deaths are announced in the Bulletin of the French Physical Society and the Popular Science Monthly:-M. Jeunet, late professor of physics; Prof. Lespiault, of the University of Bordeaux; Prof. Joseph Thimont, of the École Ste.-Geneviève and other institutions; Prof. Clemens A. Winckler, professor of chemistry at Dresden; Prof. Max Berbels, of Berlin, noted for his publications on ethnology; Major Henry F. Alvord, chief of the dairy division of the U.S. Department of Agriculture.

IN the Bulletin of the French Physical Society, No. 219 , the death is announced of Prof. Macé de Lépinay, of Marseilles, a former member of the council of the society. Prof. Macé de Lépinay's researches were mostly connected with optics, and had special reference to the determination of wave-lengths by means of interference phenomena, on the lines first laid down by Fizeau. The methods used were interference due to double refraction, interference of a direct ray with one passing through a lamina of the crystal, and interference of two rays, one passing once and the other twice through the lamina. A further series of researches dealt with the inverse problem of determining the specific mass of water. Most of the experiments were performed with sodium light. Prof. Macé de Lépinay's latest researches were conducted conjointly with M. Buisson, who proposes to complete them.

GLass hives for the observation of bees at work have been in use for many years, and latterly ants' nests have been on view at the Crystal Palace; but it may be new to many of our readers to learn that Messrs. A. W. Gamage, Ltd., of Holborn, have actually put on sale a contrivance called "The Lubbock Formicarium," which is really a 